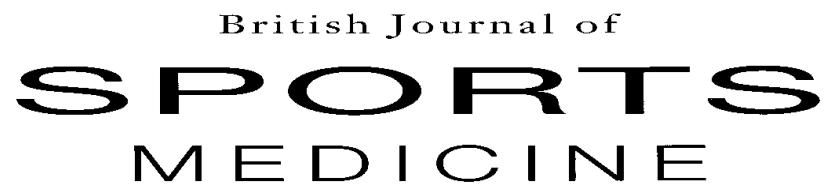

\title{
Editorials
}

Warm up

Where we are, how we do it, where we are going, and what others do. This issue sets out to create a benchmark in education. With many important recent developments in sports medicine education in the UK, we invited experts to address some of the current issues, look at methods of delivery, and give a vision of the future. To put these developments in context we present snapshots from Finland, Canada, Germany, and Australia (pages 235-244). The final stage of our educational odyssey is a survey of teaching in undergraduate medical schools (page 244) and a short paper describing the qualities required in a sports medicine specialist (page 243).

Elsewhere in this issue, we look at common sporting topics from unusual angles. Running and relaxation seem to fit well together but research into runners who practise relaxation techniques is unexpected (page 268). Osteoporosis and oestrogen are often linked but examining bone mineral density and testosterone in male runners is a new approach (page 273). Our final running paper takes a new look at pelvic tilt using measures of hip extension (page 279). We include an unusual paper addressing the needs of the blind in a reliability study of ratings of perceived exertion using Braille (page 297), and publish unexpected findings about creatine supplementation (page 284). Our case reports also record the exceptional and may not be for cyclists, fainthearted or fair (page 310).

Death is ultimately predictable, but sudden death in sport is uncommon. Most of our information on sudden death in sport is from the USA. Comprehensive epidemiological records are unusual and a study which gives some indication of the nature of the problem closer to home is especially welcome (page 258). Most people prefer to stay alive and realise that staying active can help reduce cardiovascular risk factors (page 289), but getting people active remains a difficult challenge (page 262).

\section{Editor's audit report for 1999}

The editor's report for 1999 is very late this year, which is, paradoxically, a good sign. Although the journal become bimonthly in 1999, the number and quality of submissions continues to rise and it is very difficult to find space for everything we would like to publish. As a result, this editor's report has been held over for an issue. The acceptance rate for submitted manuscripts in 1999 was 38\% and at the current rate of submission we anticipate a lower acceptance rate this current year. In table 1 and table 2 we

Table 1 Articles submitted by category

\section{Category}

\section{Original articles}

Case reports

Short reports

Editorials

Leading articles

Reviews

Education and debate

Occasional pieces

From the clinic

Letters

Fillers

Total present a summary of the nature and origin of our submissions.

Table 2 Geographical distribution of submissions

\begin{tabular}{lr} 
Area & \\
\hline United Kingdom & 131 \\
Western Europe & 5 \\
$\quad$ Belgium & 1 \\
Bulgaria & 1 \\
Denmark & 3 \\
Finland & 2 \\
France & 3 \\
Germany & 6 \\
Greece & 1 \\
Holland & 4 \\
Ireland & 6 \\
Israel & 2 \\
Norway & 4 \\
Spain & 1 \\
Sweden & 2 \\
Switzerland & 4 \\
Turkey & 32 \\
USA \& Canada & 5 \\
Japan & 29 \\
Australasia & 17 \\
Asia & 4 \\
Africa & \\
\hline
\end{tabular}




\section{In the academic game, a higher degree is the qualifying standard, and every paper is a personal best}

University departments of sports medicine are no longer a dream. Their expansion brings changes to the way sports medicine is perceived, thrusts new leaders into the spotlight, and changes the relationship between sports medicine, medical royal colleges, and sports organisations. Academic interest in sport and exercise medicine is being driven by many factors. Sport attracts money, a commodity that universities lack, and they see financial opportunity in the increasingly commercial world of academia. Sport attracts publicity and universities are waking up to the marketing potential of high level sport. Sport attracts students and, in this new commercial world of education, student numbers have a major impact on income. Increasing demand and a clear role for academic sports medicine mean that the discipline is ripe for expansion.

Universities are aware of this growing potential and every year we see increasing integration of sport and exercise medicine into undergraduate and postgraduate curricula. With increasing teaching commitment, the demand for sports medicine education will soon exceed the expertise available. At present it is often taught by an enthusiast within one of the traditional clinical specialties - such as, cardiology, orthopaedics, or rheumatology. Gradually the tension between their core duties and the additional demands of teaching sport and exercise medicine will become excessive, and we will then see the creation of new posts which are specially designed to develop sport and exercise medicine. We will need a new type of leader with particular skills and expertise for this role.

Academia is often portrayed as a rather archaic club with its own peculiar rules and regulations. But, if sports medicine is to survive in this environment, our new leaders must be able play by these rules and work in the same currency as other members of this club. Clinical skills are of considerable importance but academic credibility is gained only through the achievement of higher degrees and academic publication. As clinicians, we know that good clinical care is much more important than any published paper but this does not necessarily carry weight in the academic environment. To negotiate for resources, apply for funding, and gain curriculum time, sport and exercise medicine must be able to compete as an equal. We have some way to go.

There are established criteria in appointing senior academics to university posts and these are the standards to which future leaders should aspire. A chair would normally have a higher degree, a track record in quality research, and evidence of leadership skills. A senior lecturer would usually have a higher degree but applicants would, at the very least, have experience in research and evidence of publications. In sports medicine, few measure up to these criteria.
We have a small number of doctors working full time as sports medicine physicians yet these pioneers, who have contributed greatly to the profession, would not be rated in the academic world. Few sports medicine physicians possess a higher degree and many have no quality peer reviewed publications. These pioneers are unlikely to be among the new leadership.

But there are people associated with sport and exercise medicine who do meet academic criteria. Many orthopaedic surgeons have a higher degree. Indeed, before specialist training it would have been very difficult to progress without a higher degree, research experience, and publications. Others, including rheumatologists, physicians, general practitioners, and public health physicians may have higher degrees and research publications, although they may not work exclusively in the field of sport and exercise medicine. Sports science has evolved much more quickly as an academic discipline and our sports science colleagues are more likely to possess higher degrees, publications, and experience of working in an academic department. We could learn a lot from them.

Universities have a choice. They could choose appoint a leading clinician who has worked hard for the specialty, taught on courses, contributed to committees, and who is recognised for high quality medical care. However, it is more likely that they will opt for someone who has achieved academic excellence. Universities have to make difficult decisions when establishing academic departments. We all know of the importance of research assessment and that funding follows academic excellence. It is a harsh competitive environment. Established sports medicine physicians might have an opportunity to move into some of the first wave of academic posts, but future generations will have to tread the traditional paths to academic excellence. Those who aspire to an academic career should begin to prepare themselves to compete in this environment.

We have a choice. Future leaders in our discipline will plan their career to have the correct blend of general professional experience, higher specialist training, and academic achievement. A higher research degree-for example, an MD or PhD, will be essential, as will quality publications. Those who set off on their sports medicine career in the recent past may find this vision of the future radical, challenging, and very different from that which they imagined. But, as we read this we may already be one of yesterday's men or women. There will soon be a new generation of young lions snapping at our heels.

DOMHNALL MACAULEY

Editor,

British fournal of Sports Medicine 